\title{
NORMALIZED RELATIONSHIPS FOR DEPTH OF EMBEDMENT OF SHEET PILE WALLS AND SOLDIER PILE WALLS IN COHESIONLESS SOILS
}

\author{
SivAPALAN GAJAN ${ }^{\mathrm{i})}$
}

\begin{abstract}
Normalized, non-dimensional relationships for calculating the depths of embedment of sheet pile walls and soldier pile walls embedded in cohesionless soils are presented. Rankine theory for lateral earth pressures in active and passive conditions are used in the analyses. Relationships are presented for cantilever walls and walls propped at crest. The proposed relationships can be used in dry soil conditions and as well as in saturated soil conditions with steady state seepage. The embedment depth relationships are presented in terms of non-dimensional parameters and can be used for a variety of soil conditions, dimensions and spacing of the walls, and depths of excavation. The presented relationships are simple, easy to use, and do not require tedious calculations.
\end{abstract}

Key words: excavations, foundations, lateral earth pressures, retaining walls (IGC: H1)

\section{INTRODUCTION}

Sheet pile walls and soldier pile walls are commonly used embedded structures in geotechnical engineering practice to support retained soil or excavation. They are typically used as free-standing walls (cantilever walls) or externally supported walls (walls propped at crest) depending on the soil properties, depth of excavation, and the type of application. Several theoretical, empirical, and semi-empirical methods are used to design the depth of embedment of walls in current civil engineering practice (Coduto, 2001; Das, 2007, among others).

Many researchers have studied the load-deformation behavior of sheet pile walls and soldier pile walls embedded in a variety of soil conditions (Rowe, 1951, 1952, 1955; Tsinker, 1983; and Nataraj and Hoadley, 1984; Schriver and Valsangkar, 1996; Georgiadis and Anagnostopoulos, 1998; Guerra et al., 2004; Madabhushi and Chandrasekaran, 2005; Sheng et al., 2006; Cardoso et al., 2006). Relationships for normalized embedment depths of sheet pile walls have been previously published by Bolton et al. (1989, 1990a, 1990b), Hagerty and Nofal (1992), and Choudhury et al. (2006). Bolton et al. (1989, 1990a, 1990b) presented design charts for normalized embedment depths for cantilever and propped sheet pile walls as functions of undrained shear strength (for cohesive soils) and friction angle (for cohesionless soils). Hagerty and Nofal (1992) provided simplified design charts for normalized depth of embedment and anchor force for anchored sheet pile walls penetrating sandy soils. Choudhury et al. (2006) presented normalized relationships for calculating the embedment depths of sheet pile walls subjected to horizontal line loads.
This technical note presents normalized, non-dimensional relationships to design embedment depths for both cantilever and propped sheet pile walls and soldier pile walls embedded in dry and saturated cohesionless soils. The major differences between the past work and the work presented in this paper are that (1) the proposed relationships can be used to obtain the embedment depths of cantilever and propped walls embedded in dry cohesionless soils and saturated cohesionless soils with steady state seepage and (2) the embedment depths required for different design alternatives of the same problem, such as sheet pile walls versus soldier pile walls and cantilever walls versus propped walls, can readily be compared to one another using the proposed relationships. The relationships are presented in terms of normalized non-dimensional parameters and can be used for a variety of soil conditions, dimensions and spacing of the walls, and depths of excavation. Similar non-dimensional, normalized relationships for depth of embedment of transmission pole foundations subjected to lateral loading have been published by Gajan and McNames (2009), and are proved to be useful in estimating the embedment depths without tedious calculations.

\section{ASSUMPTIONS AND SIMPLIFICATIONS}

The results and the relationships for embedment depths presented in this technical note are obtained using the following assumptions and simplifications.

1. Soil properties are the same and uniform behind and in front of the wall.

2. Rankine theory is used to calculate the lateral soil pressures (the friction between soil and wall is

i) Assistant Professor, Department of Civil Engineering, North Dakota State University, USA (s.gajan@ndsu.edu).

The manuscript for this paper was received for review on March 26, 2010; approved on April 12, 2011.

Written discussions on this paper should be submitted before January 1, 2012 to the Japanese Geotechnical Society, 4-38-2, Sengoku, Bunkyo$\mathrm{ku}$, Tokyo 112-0011, Japan. Upon request the closing date may be extended one month. 
neglected), and hence the proposed relationships would produce slightly conservative depths of embedment.

3. The behavior of wall is represented by rigid body rotation about its toe or crest.

\section{THEORY}

\section{Sheet Pile Walls in Dry Cohesionless Soils}

Figure 1 shows the schematic of a cross section of a cantilever sheet pile wall and the lateral soil pressures acting on the wall embedded in dry or moist cohesionless soils. Cantilever walls tend to fail by rotating away from the backfill about a pivot point near the toe of the wall (fixed earth support method). The active and passive lateral soil pressures shown in Fig. 1 are idealized limit equilibrium stress distributions (Powrie, 1996). Several methods are available to calculate the location of the pivot point of the wall as the wall rotates away from the retained backfill soil. These methods use horizontal and moment equilibrium of the wall for limit equilibrium conditions, iterative calculations, and optimization methods (e.g., Madabhushi and Chandrasekaran, 2005). A simplified method, used in this study, to calculate the depth of embedment of the wall is to use moment equilibrium about the toe of the wall, assuming that the pivot point is at the toe of the wall. The calculated depth of embedment is then increased by $20 \%$ in order to provide the clearance depth beneath the pivot point (Das, 2007; Powrie, 1997). According to Rankine (1857) theory, the active and passive lateral earth pressure coefficients ( $K_{\mathrm{A}}$ and $K_{\mathrm{P}}$ respectively) can be obtained by,

$$
\begin{aligned}
& K_{\mathrm{A}}=\frac{1-\sin (\phi)}{1+\sin (\phi)} \\
& K_{\mathrm{P}}=\frac{1+\sin (\phi)}{1-\sin (\phi)}
\end{aligned}
$$

Where, $\phi$ is the friction angle of soil. Using Rankine (1857) theory and moment equilibrium about the toe of the wall, the following expression can be obtained for

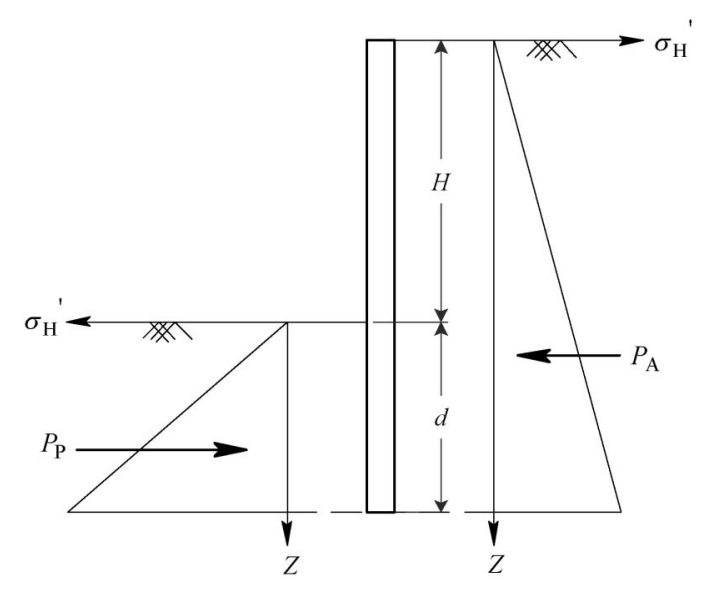

Fig. 1. Schematic of the lateral soil pressure distributions acting on sheet pile walls in cohesionless soils cantilever sheet pile walls.

$$
\begin{aligned}
& P_{\mathrm{A}}=\frac{1}{2} \cdot \gamma^{\prime} \cdot(H+d)^{2} \cdot K_{\mathrm{A}} \\
& P_{\mathrm{P}}=\frac{1}{2} \cdot \gamma^{\prime} \cdot d^{2} \cdot K_{\mathrm{P}} \\
& K_{\mathrm{A}} \cdot(H+d)^{3}=\frac{K_{\mathrm{P}}}{F S} \cdot d^{3}
\end{aligned}
$$

Where $\gamma^{\prime}$ is the effective unit weight of soil, $H$ is the depth of excavation, $d$ is the depth of embedment, and $F S$ is factor of safety, typically applied to the passive resistance of soil as the passive resistance may not be fully mobilized at failure.

A sheet pile wall, which is propped at the crest, tends to fail by rotating about the crest of the wall (free earth support method). The idealized limit equilibrium active and passive lateral soil pressure distributions of a propped wall are the same as those of a cantilever wall shown in Fig. 1. Using Rankine (1857) theory and moment equilibrium of the wall about the crest, the following expression can be obtained for propped sheet pile walls.

$$
2 \cdot K_{\mathrm{A}} \cdot(H+d)^{3}=\frac{K_{\mathrm{P}}}{F S} \cdot d^{2} \cdot(3 \cdot H+2 \cdot d)
$$

\section{Sheet Pile Walls in Saturated Cohesionless Soils}

When sheet pile walls are used to support saturated cohesionless soil deposits, in addition to the effective lateral soil pressures, the pore water pressures will also act on the wall. The accurate steady state equilibrium pore water pressures can be obtained by sketching a seepage flownet. However a linear seepage approximation method can also be used to estimate the pore water pressures around the sheet pile wall. In linear seepage approximation method, the fall in total head is assumed to be distributed linearly around the wall (Powrie, 1997). Symons (1983) showed that this method produces reasonably approximate results for pore water pressures during steady state seepage. Figure 2 shows the schematic of the approxi-

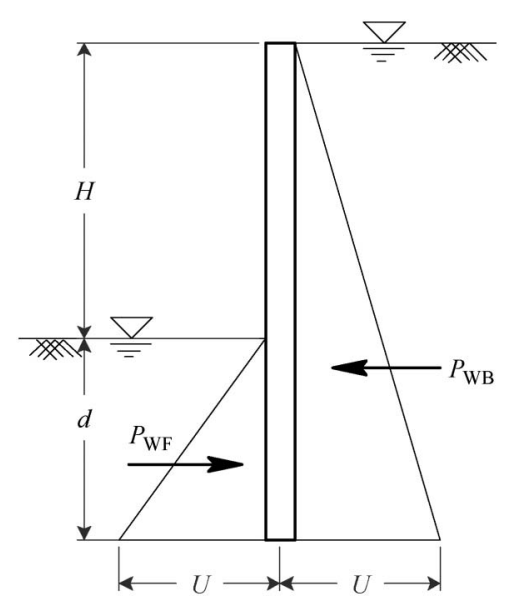

Fig. 2. Schematic of the water pressure distributions acting around the sheet pile walls in saturated cohesionless soils (linear seepage approximation method) 
mate distribution of the equilibrium pore water pressure around the wall during seepage $\left(P_{\mathrm{WB}}\right.$ : pore water force behind the wall and $P_{\mathrm{WF}}$ : pore water force in front of the wall). Using linear seepage approximation method, the total head at the toe of the wall $(T)$ can be obtained by,

$$
T=H \cdot \frac{d}{H+2 \cdot d}
$$

Using the total head (Eq. (7)) and the elevation head (assuming that the datum is located at the ground surface location in front of the wall), the pore water pressure at the toe of the wall $(U)$ can be obtained by,

$$
U=\gamma_{\mathrm{w}} \cdot d \cdot\left[1+\frac{H}{H+2 \cdot d}\right]
$$

Where $\gamma_{\mathrm{w}}$ is the unit weight of the water. Using the pore water pressure distribution shown in Fig. 2, the effective lateral soil pressures calculated by Eqs. (3) and (4), and the moment equilibrium about the toe of the wall, the following expression can be obtained for cantilever sheet pile walls.

$$
\left[P_{\mathrm{A}}+\frac{1}{2} \cdot U \cdot(H+d)\right] \cdot(H+d)=\left[\frac{P_{\mathrm{P}}}{F S}+\frac{1}{2} \cdot U \cdot d\right] \cdot d
$$

For a wall propped at crest, by taking moment equilibrium about crest or anchor point of the wall, the following expression can be obtained.

$$
\begin{aligned}
2 \cdot & {\left[P_{\mathrm{A}}+\frac{1}{2} \cdot U \cdot(H+d)\right] \cdot(H+d) } \\
& =\left[\frac{P_{\mathrm{P}}}{F S}+\frac{1}{2} \cdot U \cdot d\right] \cdot(3 \cdot H+2 \cdot d)
\end{aligned}
$$

\section{Soldier Pile Walls in Dry Cohesionless Soils}

While sheet pile walls are continuous, soldier piles are driven at regular intervals with spacing in between them. The spacing between soldier piles is then typically supported by wooden blocks above the base of the excavation. Therefore, for the limit equilibrium analysis of a soldier pile, the tributary area over which the active pressure acts is the spacing between piles $(S)$ and the tributary area over which the passive pressure acts is equal to three times the width of the soldier pile $(3 \cdot D)$. It should be noted that the active lateral pressure above the base of the excavation acts over the tributary area $S$, while the active lateral pressure beneath the base of excavation acts over a tributary area smaller than $S$. However, for simplification and conservative embedment depths, it is assumed the active lateral pressure acts over the tributary area $S$ for the whole length of the wall $(H+d)$. For passive resistance beneath the base of excavation, the zone of influence is assumed to be three times the width of the soldier pile as suggested in the Earth Retention Systems Handbook (Macnab, 2002). Using the same method described in sheet pile walls, the following equation can be obtained for cantilever soldier pile walls.

$$
K_{\mathrm{A}} \cdot(H+d)^{3} \cdot S=\frac{K_{\mathrm{P}}}{F S} \cdot d^{3} \cdot 3 \cdot D
$$

For soldier pile walls that are propped at crest, the following expression can be obtained for limit equilibrium.

$$
2 \cdot S \cdot K_{\mathrm{A}} \cdot(H+d)^{3}=3 \cdot D \cdot \frac{K_{\mathrm{P}}}{F S} \cdot d^{2} \cdot(3 \cdot H+2 \cdot d)
$$

Note that saturated soil conditions are not considered for soldier pile walls, as they are not suitable to support saturated soil conditions with seepage flow. Also note that the calculated embedment depth of cantilever sheet pile walls and cantilever soldier pile walls are multiplied by a factor of 1.2 in order to compensate the error associated with the pivot point location used in moment equilibrium (Powrie, 1997).

\section{RESULTS}

\section{Sheet Pile Walls in Dry Cohesionless Soils}

Equation 5 can be rearranged (Eq. (13)) to obtain a closed-form relationship between normalized depth of embedment $(d / H)$ and normalized soil strength $\left(K_{\mathrm{P}}^{2} / F S\right)$ for cantilever sheet pile walls embedded in dry cohesionless soils.

$$
\frac{d}{H}=(1.2) \cdot\left[\left(\frac{K_{\mathrm{P}}^{2}}{F S}\right)^{0.33}-1\right]^{-1}
$$

Figure 3 plots the relationship between $d / H$ and $K_{\mathrm{P}}^{2}$ $/ F S$ as obtained from Eq. (13). For propped sheet pile walls embedded in dry cohesionless soils (Eq. (6)), a closed form solution for $d / H$ cannot be obtained. For this case, several numerical calculations were performed to obtain the solutions for $d / H$. In these calculations, the friction angle was varied from 10 to 50 degrees, the depth of excavation was varied from $0.1 \mathrm{~m}$ to $20 \mathrm{~m}$, and the factor of safety was varied from 1 to 4 . For each combination of these parameters, the normalized depth of embedment $(d / H)$ was calculated and the calculated results for $d / H$ are plotted in Fig. 3. Also plotted in Fig. 3 is a best fit equation for the relationship between $d / H$ and $K_{\mathrm{P}}^{2} / F S$ for propped sheet pile walls embedded in dry cohesionless soils. The equation of this best fit line has the similar format as Eq. (13), and presented in Eq. (14).

$$
\frac{d}{H}=\left[\left(\frac{K_{\mathrm{P}}^{2}}{F S}\right)^{0.55}-1\right]^{-1}
$$

\section{Sheet Pile Walls in Saturated Cohesionless Soils}

For sheet pile walls embedded in saturated cohesionless soils, several numerical calculations were carried out to solve for $d / H$ using Eqs. (9) and (10) for cantilever walls and propped walls respectively. In these calculations, the friction angle was varied from 10 to 50 degrees, the depth of excavation was varied from $0.1 \mathrm{~m}$ to $20 \mathrm{~m}$, the factor of safety was varied from 1 to 4 , and the ratio of $\left(\gamma_{\mathrm{w}} / \gamma^{\prime}\right)$ was assumed to be 1.0 (a reasonable assumption for average saturated cohesionless soils). It should be noted that the calculated results for $d / H$ are not very sensitive 

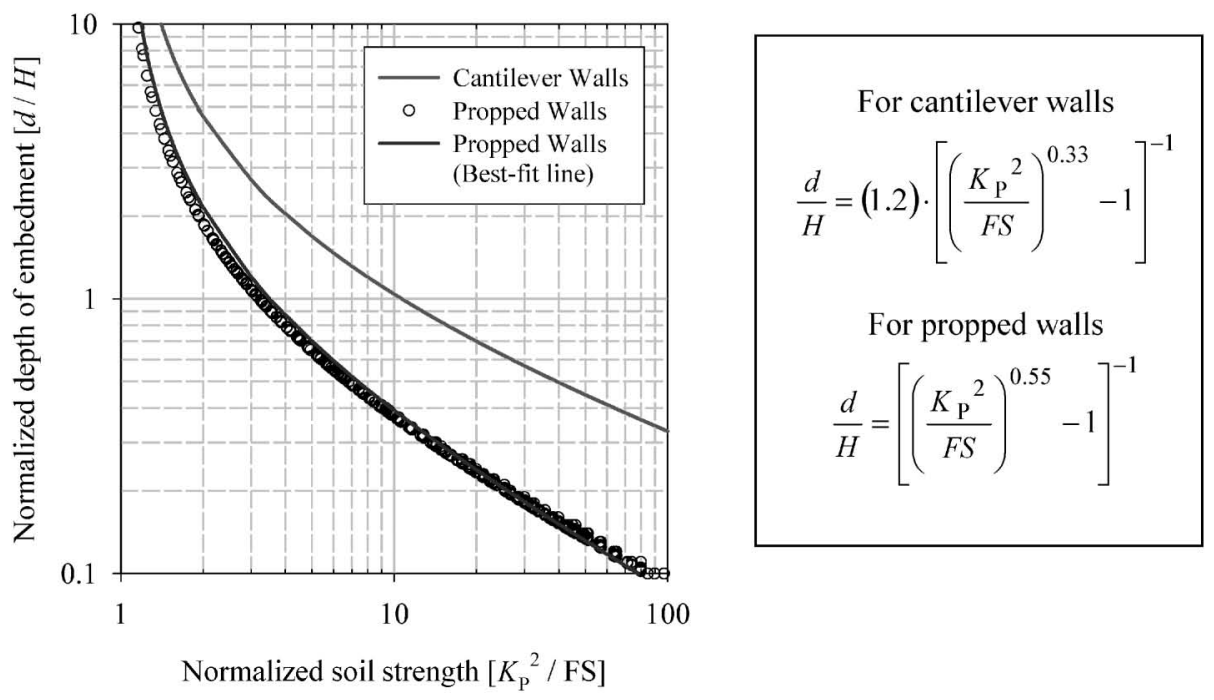

Normalized soil strength $\left[K_{\mathrm{P}}^{2} / \mathrm{FS}\right]$

Fig. 3. Relationship between normalized embedment depth and normalized strength for sheet pile walls in dry cohesionless soils

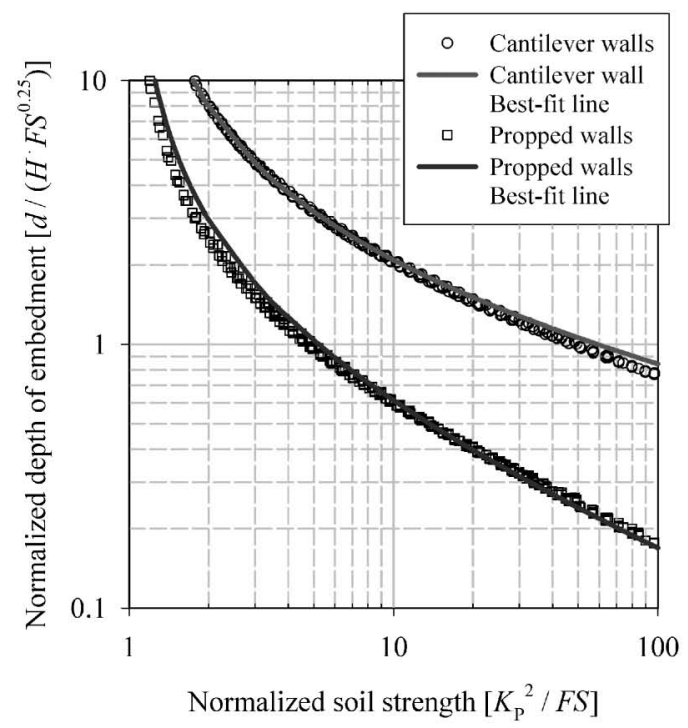

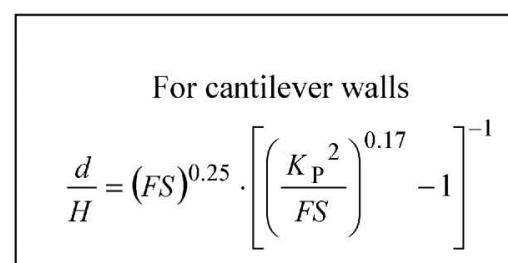

For propped walls

$$
\frac{d}{H}=(F S)^{0.25} \cdot\left[\left(\frac{K_{\mathrm{P}}^{2}}{F S}\right)^{0.42}-1\right]^{-1}
$$

Fig. 4. Relationship between normalized embedment depth and normalized strength for sheet pile walls in saturated cohesionless soils

to the ratio of $\gamma_{\mathrm{w}} / \gamma^{\prime}$ (for the practical range of values of $\left.\gamma^{\prime}\right)$. Figure 4 plots the calculated results for $[d /(H$. $\left.F S^{0.25}\right)$ ] as a function of normalized soil strength $\left(K_{\mathrm{P}}^{2} /\right.$ $F S)$. Also plotted in Fig. 4 are two best-fit equations: cantilever walls (Eq. (15)) and propped walls (Eq. (16)). Note that $d /\left(H \cdot F S^{0.25}\right)$ is used for normalized embedment depth, as the normalized results produce uniform results for various $F S$ values.

$$
\begin{aligned}
& \frac{d}{H}=(F S)^{0.25} \cdot\left[\left(\frac{K_{\mathrm{P}}^{2}}{F S}\right)^{0.17}-1\right]^{-1} \\
& \frac{d}{H}=(F S)^{0.25} \cdot\left[\left(\frac{K_{\mathrm{P}}^{2}}{F S}\right)^{0.42}-1\right]^{-1}
\end{aligned}
$$

\section{Soldier Pile Walls in Dry Cohesionless Soils}

Equation (11) can be rearranged (Eq. (17)) to obtain a relationship between normalized depth of embedment $(d / H)$ and normalized soil strength $\left[\left(K_{\mathrm{P}}^{2} / F S\right) \cdot(D / S)\right]$ for cantilever soldier pile walls embedded in dry cohesionless soils.

$$
\frac{d}{H}=(1.2) \cdot\left[1.44 \cdot\left(\frac{K_{\mathrm{P}}^{2}}{F S} \cdot \frac{D}{S}\right)^{0.33}-1\right]^{-1}
$$

Figure 5 plots the relationship between $d / H$ and $\left[\left(K_{\mathrm{P}}^{2} /\right.\right.$ $F S) \cdot(D / S)$ ] as obtained from Eq. (17). For propped soldier pile walls embedded in dry cohesionless soils (Eq. (12)), a closed form solution for $d / H$ cannot be obtained. For this case, several numerical calculations were performed to obtain the solutions for $d / H$. In these calculations, the friction angle was varied from 10 to 50 degrees, the depth of excavation was varied from $0.1 \mathrm{~m}$ to $20 \mathrm{~m}$, the spacing to width ratio of the wall $(S / D)$ was varied from 3 to 10 , and the factor of safety was varied from 1 to 4 . For each combination of these parameters, the normalized depth of embedment $(d / H)$ was calculated and 

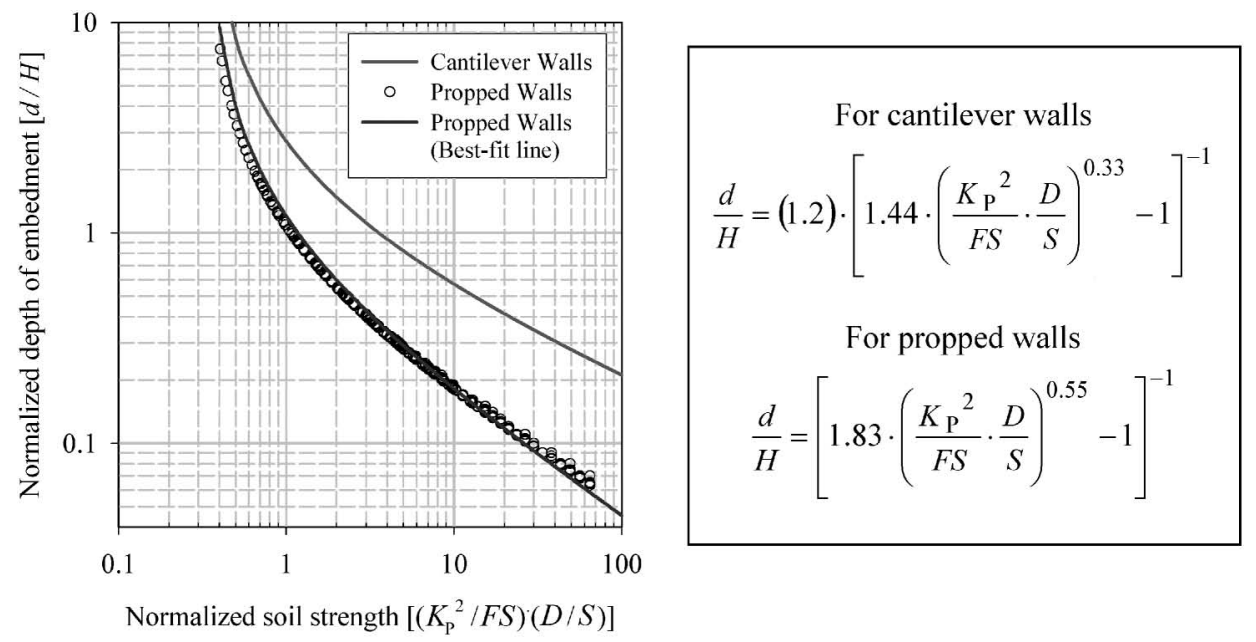

Normalized soil strength $\left[\left(K_{\mathrm{p}}^{2} / F S\right)(D / S)\right]$

Fig. 5. Relationship between normalized embedment depth and normalized strength for soldier pile walls in dry cohesionless soils

the calculated results for $d / H$ are plotted in Fig. 5. Also plotted in Fig. 5 is a best fit equation for the relationship between $d / H$ and $\left[\left(K_{\mathrm{P}}^{2} / F S\right) \cdot(D / S)\right]$ for propped soldier pile walls embedded in dry cohesionless soils. The equation of this best fit line has the similar format as Eq. (17), and presented in Eq. (18).

$$
\frac{d}{H}=\left[1.83 \cdot\left(\frac{K_{\mathrm{P}}^{2}}{F S} \cdot \frac{D}{S}\right)^{0.55}-1\right]^{-1}
$$

\section{LIMITATIONS}

It should be noted that the proposed method for saturated cohesionless soils is only applicable when the water table is at the ground surface (both sides of the wall). If the water table is located below the backfill ground surface, the proposed method would yield conservative results.

\section{SUMMARY AND CONCLUSIONS}

Normalized, non-dimensional relationships for calculating the depths of embedment of sheet pile walls and soldier pile walls embedded in cohesionless soils are presented. The wall itself is assumed to rotate as a rigid body and the limit equilibrium theories are used to calculate the depths of embedment of cantilever walls (fixed earth support method) and walls propped at crest (free earth support method). Rankine theory was used to calculate the lateral earth pressures on the wall and linear seepage approximation method was used to calculate the pore water pressures acting around the wall during steady state seepage in saturated cohesionless soils.

The relationships for normalized depth of embedment $\left(d / H\right.$ or $\left.\left[d /\left(H \cdot F S^{0.25}\right)\right]\right)$ are presented as functions of normalized strength of soil $\left(K_{\mathrm{P}}^{2} / F S\right.$ or $\left.\left[\left(K_{\mathrm{P}}^{2} / F S\right) \cdot(D / S)\right]\right)$. The proposed relationships can be used to calculate the required depths of embedment in cohesionless soils with a wide range of friction angle $\left(K_{\mathrm{P}}\right)$ in dry soils as well as in saturated soils with steady state seepage, for a wide range of depth of excavation $(H)$, and for a wide range of spacing to width ratio $(S / D)$ in case of soldier piles. In addition, the user has the option to provide a desired factor of safety for passive resistance of soil $(F S)$ when calculating the depth of embedment. The embedment depths required for different design alternatives of the same problem, such as sheet pile walls versus soldier pile walls and cantilever walls versus propped walls, can readily be compared to one another using the proposed relationships. The proposed relationships are simple, easy to use, and eliminate the tedious calculations typically used to calculate the depth of embedment in design.

\section{REFERENCES}

1) Bolton, M. D., Powrie, W . and Symons, I. F. (1989): The design of stiff in-situ walls retaining over consolidated clay-Part I: shortterm behavior, Ground Engineering, 22(8), 44-47.

2) Bolton, M. D., Powrie, W. and Symons, I. F. (1990a): The design of stiff in-situ walls retaining over consolidated clay-Part II: shortterm behavior (continued), Ground Engineering, 22(9), 34-40.

3) Bolton, M. D., Powrie, W. and Symons, I. F. (1990b). The design of stiff in-situ walls retaining over consolidated clay-Part II: longterm behavior, Ground Engineering, 23(2), 22-28.

4) Cardoso, A. S., Guerra, N. M., Antao, A. N. and Fernandes, M. M. (2006): Limit analysis of anchored concrete soldier pile walls in clay under vertical loading, Canadian Geotechnical Journal, 43(5), 516-530.

5) Choudhury, D., Singh, S. and Goel, S. (2006): New approach for analysis of cantilever sheet pile with line load, Journal of Geotechnical and Geoenvironmental Engineering, ASCE, 43(5), 540-549.

6) Coduto, D. P. (2001): Foundation Design: Principles and Practices, Upper Saddle River, New Jersey, Prentice Hall.

7) Das, B. M. (2007): Principles of Foundation Engineering, 6th Edition, Pacific Grove, Brooks/Cole Publishing Company.

8) Gajan, S. and McNames, C. (2010): Improved design of embedment depths for transmission pole foundations subjected to lateral loading, Practice Periodical in Structural Design and Construction, ASCE, 15(1), 73-81.

9) Georgiadis, M. and Anagnostopoulos, C. (1998): Lateral pressure on sheet pile wall due to strip load, Journal of Geotechnical and Geoenvironmental Engineering, ASCE, 124(1), 95-98.

10) Guerra, N. M., Cardoso, A. S., Fernandes, M. M. and Correia, A. 
G. (2004): Vertical stability of anchored concrete soldier pile walls in clay, Journal of Geotechnical and Geoenvironmental Engineering, ASCE, 130(12), 1259-1270.

11) Hagerty, D. J. and Nofal, M. M. (1992): Design aids-anchored bulkheads in sand, Canadian Geotechnical Journal, 29(5), 789-795.

12) Madabhushi, G. and Chandrasekaran, V. S. (2005): Rotation of cantilever sheet pile walls, Journal of Geotechnical and Geoenvironmental Engineering, ASCE, 131(2), 202-212.

13) Mcnab, A. (2002): Earth Retention Systems Handbook, McGrawHill Handbooks Publications, 535.

14) Nataraj, M. S. and Hoadley, P. G. (1984): Design of anchored bulkheads in sand, Journal of Geotechnical and Geoenvironmental Engineering, ASCE, 110(4), 505-515.

15) Powrie, W. (1996): Limit equilibrium analysis of embedded retaining walls, Geotechnique, 46(4), 709-723.

16) Powrie, W. (1997): Soil Mechanics: Concepts and Applications, London, UK, E and FN Spon, An imprint of Chapman and Hall.

17) Rankine, W. (1857): On the Stability of Loose Earth, Philosophical Transactions of the Royal Society of London, 147.
18) Rowe, P. W. (1951): Cantilever sheet piling in cohesionless soil, Engineering, 172, 316-319.

19) Rowe, P. W. (1952): Anchored sheet pile walls, Proc. Institute of Civil Engineers 1, Part I, 27-70.

20) Rowe, P. W. (1955): A theoretical and experimental analysis of sheet pile walls, Proc. Institute of Civil Engineers 4, Part I, 32-69.

21) Schriver, A. B. and Valsangkar, A. J. (1996): Anchor rod forces and maximum bending moments in sheet pile walls using the factored strength approach, Canadian Geotechnical Journal, 33(5), 815-821.

22) Sheng, D., Sun, D. and Matsuoka, H. (2006): Cantilever sheet pile wall modeled by frictional contact, Soils and Foundations, 46(1), 29-37.

23) Symons, I. F. (1983): Assessing the stability of a propped in situ retaining wall in over-consolidated clay, Proc. Institution of Civil Engineers, Part 2, 75, 617-633.

24) Tsinker, G. P. (1983): Anchored sheet pile bulkheads: Design practice, Journal of Geotechnical and Geoenvironmental Engineering, ASCE, 109(8), 1021-1038. 